\title{
Prevalence of Pathogenic Bacteria in Shrimp Samples Collected from Hatchery, Local Markets and the Shrimp Processing Plant
}

\author{
M. Majibur Rahman, Farjana Rahman, Farzana Afroze, Farzana Yesmin, Kazi Kaniz Fatema, Kamal Kanta \\ Das, Rashed Noor* \\ Department of Microbiology, Stamford University Bangladesh, 51 Siddeswari Road, Dhaka-1217, Bangladesh.
}

\begin{abstract}
Export quality frozen shrimps comprise as one of the major economic interests in Bangladesh. During cultivation or processing and packaging, microbial condition is an important issue to maintain the quality of shrimps. Eight shrimp samples, of which, one from hatchery, 3 from local markets and 4 processed export quality samples were studied for microbiological risk assessment (MRA). One hatchery, three market and two export quality shrimp samples were found to contain bacterial pathogens probationary identified as Escherichia coli, Klebsiella spp., Vibrio spp., Aeromonas spp., Pseudomonas spp., Listeria spp., Shigella-like organisms, Staphylococcus aureus, and Salmonella spp. and two other processed export quality shrimp samples were completely free of pathogens of any type. Surprisingly, the later two processed export quality shrimp samples showed antibacterial activity against $E$. coli, Klebsiella sp. and Vibrio sp.
\end{abstract}

Key Words: Shrimp; pathogenic microorganisms; export quality frozen shrimp, antimicrobial activity

\section{Introduction}

Shrimp cultivation and export in Bangladesh have undergone rapid expansion over the last two decades. Between 1983 and 2003, the volume of shrimp and prawn cultivated in land aquaculture

has increased more than 14 times $^{1}$. In 2003, the Department of Fisheries estimated that there had been approximately 203,071 hectares of coastal shrimp farms producing an average of 75,167 metric tons of shrimp annually ${ }^{1}$. Export of shrimps has given second priority in terms of earning foreign currency after the garment industry.

Currently, 36 shrimp species are harvested and cultivated in Bangladesh. The two main species of shrimps are the bagda (shrimp) and the golda (prawn). Chittagong-Cox's Bazar and Khulna-Shatkira-Bagherat regions usually dominate shrimp production. These two regions account for approximately 95 percent of the total area dedicated to shrimp culture. Brackish water aquaculture is widespread throughout Satkhira, Khulna, Cox's Bazar, and Bagerhat. Penaeus monodon and Macrobrachium rosenbergii, the two major species of bagda and golda, respectively, are cultivated in these areas. Macrobrachium rosenbergii, the most popular freshwater prawn, is largely produced in the southwest region of the country. There has been an increase in awareness about the nutritional value and health benefits of fish consumption in the last two decades. On the other hand, seafood is also known to have been responsible for a significant percentage of food-borne diseases ${ }^{2}$, ${ }^{3}$. In the seafood related outbreaks, a wide variety of viruses, bacteria, and parasites have been reported. Consumption of raw or undercooked seafood is the factor most commonly associated with infection ${ }^{4}$. There is epidemiological evidence, particularly from Japan, that consumption of raw fish is indeed the cause of many outbreaks of food-borne diseases. Biotoxins and histamines make up a large proportion of these outbreaks ${ }^{5}$. Though viruses are the most common cause of seafood related infections, most of the hospitalisation and deaths are due to bacterial agents ${ }^{4}$. As a consequence, food safety and quality aspects in trade became important, since fresh food is more prone to microbiological contamination ${ }^{6}$. Therefore, with the growing importance of shrimp as one of the major export items from Bangladesh, it is important to carefully maintain the microbiological quality of the exported item through appropriate measures.

In this perspective, we attempted to monitor the pathogenic load randomly in export quality shrimps. However, microbiological proliferation in the shrimp is mainly dependent on the condition of transport, handling and processing. Frozen shrimps are often contaminated after catching ${ }^{7}$. Handling of raw materials influences the bacteriological quality of frozen shrimps. Insufficiently iced and improperly storage of shrimps at higher temperature enhances the growth of microorganisms

${ }^{*}$ Corresponding author:

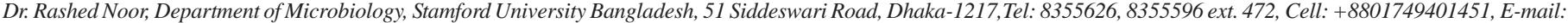
noor.rashed@yahoo.com 
responsible for microbiological changes. Thus, the quality of shrimp and frozen fish of desirable food standards has to be ensured with necessary measures. Frozen shrimps are normally subjected to preshipment inspection based on physical and sensory characteristics followed by microbiological characteristics. Thus, our study was designed to i) identify and enumerate the pathogens associated with the shrimps dedicated for export, with the shrimps from hatchery and from local markets; ii) to compare the microbiological data among the various shrimp samples studied; and iii) finally to assess whether is any residual antimicrobial agents left in the sample even after processing.

\section{Materials and Methods}

\section{Sample Collection}

Export quality frozen shrimp samples were collected from Conception Sea Food Ltd., Cox's Bazar and Seamark (BD) Limited, Chittagong, Bangladesh. Hatchery shrimp was collected from Shatkhira, Khulna. Market shrimps were collected from Malibagh bazaar, Shantinagar market and Agora departmental store. One fresh (Macrobrachium rosenbergi, sample code ES 4), 2 sea water (Penaeus monodon, sample code ES 1, 2 \& 3) export quality frozen shrimp samples, 1 hatchery and 3 market shrimp samples were subjected to microbiological testing.

\section{Sample Processing}

Ten grams of samples from different parts (head, body and head body) of each shrimp were aseptically collected and were transferred to sterile containers. The sample was transferred to $90 \mathrm{ml}$ sterile normal saline and was homogenized. Then $1 \mathrm{ml}$ of the homogenized suspension was transferred to $9 \mathrm{ml}$ normal saline and then serial dilution (10-fold) was carried out up to $10^{6}$ consecutively.

Isolation of pathogenic microorganisms from shrimp sample Escherichia coli and Klebsiella spp.

To isolate Escherichia coli and Klebsiella spp. from each $10^{-1}$ to $10^{-3}$ dilution tubes, $0.1 \mathrm{ml}$ suspension was spread on the surface of MacConkey agar medium and was incubated at 37 ${ }^{\circ} \mathrm{C}$ for $24 \mathrm{~h}$. After incubation, the plate was observed for characteristic colonies. The presence of E. coli was further confirmed by the appearance of bluish-black colonies with green metallic sheen on Eosin-Methylene Blue (EMB) agar medium.

\section{Salmonella spp., Shigella-like organisms and Vibrio spp.}

One $\mathrm{ml}$ of homogenized sample was transferred to $9 \mathrm{ml}$ of selenite cystine broth and alkaline peptone water $\left(10^{-1}\right.$ dilution) for enrichment of Salmonella, Shigella like organisms and Vibrio spp., respectively, which were then incubated at $37^{\circ} \mathrm{C}$ for $6 \mathrm{~h}$. Then $1 \mathrm{ml}$ of enriched broth was subjected to 10 -fold serial dilution up to $10^{-2}$ to $10^{-6}$ in $9 \mathrm{ml}$ of normal saline. From each $10^{-4}$ to $10^{-6}$ dilution tubes, $0.1 \mathrm{ml}$ of suspension was spread onto XLD and TCBS agar plates. After incubated at $37^{\circ} \mathrm{C}$ for $24 \mathrm{~h}$, characteristic colonies were detected and counted.

\section{Clostridium perfringens}

Each sample was mixed in sterile saline in a ratio of 1:8 and was heated at $80^{\circ} \mathrm{C}$ for 15 minutes in order to kill vegetative cells. Then $1 \mathrm{ml}$ heated suspension was allowed to grow at $37^{\circ}$ $\mathrm{C}$ in $9 \mathrm{ml}$ fluid thioglycolate broth for $4 \mathrm{hrs}$. Afterward, $1 \mathrm{ml}$ of enriched broth was subjected to 10 -fold serial dilution from $10^{1}$ to $10^{-6}$ in $9 \mathrm{ml}$ of normal saline. From each $10^{-4}$ to $10^{-6}$ dilution tubes, $0.1 \mathrm{ml}$ of suspension was pour plated on perfringens agar medium. The plates were then incubated at 37 ${ }^{\circ} \mathrm{C}$ in a candle jar for $48 \mathrm{hrs}$. Colonies appeared as black were detected and counted as suspected Clostridium perfringens.

\section{Listeria monocytogenes}

To isolate Listeria monocytogenes from $10^{-3}, 10^{-5}, 10^{-6}$ dilution tubes, $0.1 \mathrm{ml}$ suspension was spread onto Listeria isolation media and was incubated at $37^{\circ} \mathrm{C}$ for $24 \mathrm{~h}$. Colonies appeared as olive green were detected and counted as suspected Listeria monocytogenes.

\section{Probationary identification of the bacterial isolates}

Different types of colonies in various culture media were observed carefully. Morphological characteristics including color, shape, elevation, surface texture, opacity, etc of the colonies on different media were recorded. The size and shape of the cells were observed by Gram staining. Finally, according to the Manual of Methods for General Bacteriology (ASM, 1981), a series of biochemical tests were performed to probationary identify the bacteria of interest.

\section{Tests for antimicrobial activity}

Muller Hinton agar was seeded with test organisms (E. coli, Klebsiella spp. and Vibrio spp.). Sterile paper discs (6.0 mm) were impregnated each with $10 \mu \mathrm{l}$ of homogenized shrimp samples and were placed on the seeded agar plates. Plates were then incubated at $37^{\circ} \mathrm{C}$ for $24 \mathrm{~h}$, and the clear zones of inhibition (in $\mathrm{mm}$ ) around the disc were measured with the slide calipers and the results were recorded.

\section{Results}

Microbiological assessment of different samples (hatchery, local market and processed export quality)

Presence of pathogenic microorganisms was examined through the conventional cultural and biochemical methods. Various types of selective media that encourage the growth of specific microorganisms were also used. XLD agar was used for Salmonella and Shigella, TCBS agar for Vibrio spp. and MSA agar media was used for Staphylococcus spp. In XLD agar media, black centered colonies were observed that were assumed as 
Salmonella spp. In TCBS agar media green and yellow colonies were observed. Yellow colonies were suspected as Vibrio cholerae and green colonies were suspected as Aeromonas and Vibrio parahaemolyticus as it had no ability to ferment sucrose in the TCBS agar. Olive green colonies with black center hollow were identified as Listeria spp. on Listeria identification agar media. Colonies from different selective media were subcultured and subjected to extensive biochemical test for confirmation. Results are given in the Table 1.

Comparison among results of pathogenic bacteria isolated from local market, hatchery and processed export quality frozen shrimps (promoted)

A comparative study was carried out to assess the quality of supplied shrimp samples collected from local markets, hatchery and shrimp industries. Pathogenic microorganisms associated with health hazards were probationary identified as E. coli, Klebsiella spp., Vibrio spp., Listeria spp., Salmonella spp. and Staphylococcus aureus. The results are summarized in Tables
$1 \& 2$. A number of bacterial pathogens were found from shrimp samples collected from different local markets and hatchery. No pathogens were detected from processed export quality frozen shrimp in samples 1 and 2. The higher pathogenic bacterial load was observed in case of processed export quality frozen shrimp samples 3 and 4.

\section{Tests for antimicrobial activity}

The complete absence of pathogens led us to assume that the two processed export quality shrimp (ES1 \& 2) samples might consist of some chemicals inhibitory against pathogens. Thus, we turned our interest to examine whether the sample contained any antimicrobial agent. Thus, the shrimp samples were tested against three common test organisms (E. coli, Klebsiella spp. and Vibrio spp.). Complete zone of inhibition was observed around test organisms after introduction of processed export quality shrimp samples but no zone of inhibition was found in case of hatchery shrimp (Table 3).

Table 1. Biochemical tests confirmative of the presence of the specific pathogens

\begin{tabular}{|c|c|c|c|c|c|c|c|c|c|c|c|}
\hline \multirow[t]{2}{*}{ Colonies on media } & \multicolumn{3}{|c|}{ TSI } & \multirow[b]{2}{*}{$\mathrm{H}_{2} \mathrm{~S}$} & \multirow{2}{*}{$\begin{array}{c}\text { Catalase } \\
\text { test }\end{array}$} & \multirow{2}{*}{$\begin{array}{c}\text { Oxidase } \\
\text { test }\end{array}$} & \multirow{2}{*}{$\begin{array}{c}\text { Indole } \\
\text { production }\end{array}$} & \multirow[t]{2}{*}{ MR } & \multirow[t]{2}{*}{ VP } & \multirow{2}{*}{$\begin{array}{c}\text { Citrate } \\
\text { Utilization }\end{array}$} & \multirow[t]{2}{*}{ Suspected organism } \\
\hline & Slant & Butt & Gas & & & & & & & & \\
\hline Mac(Pink) & A & $\mathrm{A}$ & + & - & + & - & + & + & - & + & E. coli \\
\hline Listeria media (black) & - & - & - & - & - & - & - & - & - & - & Listeria monocytogenes \\
\hline TCBS (Large Yellow) & A & A & + & - & + & - & + & + & - & + & Aeromonas spp. \\
\hline
\end{tabular}

TSI: Triple Sugar Iron A: Acidic Reaction

MR: Methyl Red K: Alkaline reaction

VP: Voges Praskeur $\quad+$ : Positive

- : Negative

Table 2. Comparison among the pathogenic load of the shrimp samples from market, hatchery and from processed export quality frozen shrimps

\begin{tabular}{|c|c|c|c|c|c|c|c|c|}
\hline \multirow[t]{2}{*}{ Isolated Pathogenic Bacteria } & \multicolumn{8}{|c|}{ Count (cfu/g) } \\
\hline & MB & SM & ADS & ES-1 & ES-2 & ES-3 & ES-4 & HS \\
\hline E. coli & $8 \times 10^{5}$ & $1.20 \times 10^{6}$ & $1.00 \times 10^{5}$ & 0 & 0 & $1 \times 10^{4}$ & $1 \times 10^{4}$ & $1.2 \times 10^{7}$ \\
\hline Kliebsiella spp & $1 \times 10^{5}$ & 0 & 0 & 0 & 0 & $4 \times 10^{4}$ & $6.5 \times 10^{5}$ & $2.0 \times 10^{7}$ \\
\hline Vibrio spp. & $1.15 \times 10^{6}$ & $1.26 \times 10^{7}$ & $6.50 \times 10^{5}$ & 0 & 0 & $3 \times 10^{4}$ & $4.5 \times 10^{5}$ & $2.9 \times 10^{5}$ \\
\hline Aeromonas spp. & 0 & 0 & 0 & 0 & 0 & 0 & 0 & $2.7 \times 10^{5}$ \\
\hline Pseudomonas Spp. & 0 & 0 & 0 & 0 & 0 & 0 & 0 & $5.5 \times 10^{7}$ \\
\hline Shigella like organisms & $3.00 \times 10^{6}$ & $2.00 \times 10^{5}$ & $1.02 \times 10^{7}$ & 0 & 0 & 0 & 0 & 0 \\
\hline Salmonella spp. & 0 & 0 & 0 & 0 & 0 & 0 & $2 \times 10^{4}$ & 0 \\
\hline Clostridium spp. & 0 & 0 & 0 & 0 & 0 & 0 & 0 & 0 \\
\hline Staphylococcus aureus & $4.58 \times 10^{7}$ & $6.57 \times 10^{7}$ & $2.09 \times 10^{7}$ & 0 & 0 & $1.50 \times 10^{7}$ & $1.01 \times 10^{7}$ & 0 \\
\hline Listeria spp. & 0 & $7.85 \times 10^{7}$ & 0 & 0 & 0 & $3 \times 10^{4}$ & $4.5 \times 10^{5}$ & $3 \times 10^{7}$ \\
\hline
\end{tabular}


Table 3. Antimicrobial activity exhibited by export quality shrimp samples

\begin{tabular}{lccc}
\hline Sample code & \multicolumn{3}{c}{ Zone of Inhibition $(\mathrm{mm})$ against pathogens } \\
\cline { 2 - 4 } & E. coli & Klebsiella & Vibrio \\
\hline HS-1 & Nil & Nil & Nil \\
ES-1 & 24 & 18 & 15 \\
ES-2 & 19 & 17 & 12 \\
\hline
\end{tabular}

HS: Hatchery shrimp

ES: Export quality frozen shrimp Nil: no zone of inhibition found around the sample used

\section{Discussion}

Fisheries sector plays an important role in the socio-economic development of Bangladesh. This is the second highest source of earning foreign currencies and providing direct or indirect employment to $10 \%$ of the total population of the country ${ }^{1}$. The quality of the processed products largely depends on the quality of raw materials and it is difficult to preserve freshness of raw materials when there is a long gap between the harvesting and processing time. During this period, shrimps continue to deteriorate ${ }^{8}$. The time interval between the landings of shrimps and their arrival at the processing plants is very important ${ }^{9}$. Improper handling and inadequate processing result in microbial growth which causes spoilage of food products. Present study was thus carried out to assess the pathogenic load in the shrimp samples of export quality.

Bangladesh exports mainly frozen shrimp and different types of fresh and marine water fishes. The recent introduction of the Hazard Analysis Critical Control Point (HACCP) system and European Union hygienic regulations in seafood industries will pave the way for the production of safe and high quality seafood. Bangladesh frozen shrimp exporters continue to have both real and perceived problems with buyers in the USA, the European Union and Japan, concerning the safety and quality of their products. Because many fish processing plants in Bangladesh do not follow the HACCP system and EU hygienic regulations for which many of them have been banned and the export of shrimps, fish and fish products is reduced ${ }^{10}$. From the standpoint of above observations, we have tried to assess the quality of our shrimp products and our study detected the presence of pathogens (Escherichia coli, Klebsiella spp., Vibrio cholerae, Listeria monocytogenes) associated with enteric diseases in human from shrimp sample collected from hatchery and market which exceed the standard level of ICMSF (International Commission on Microbial Specifications for Foods). Pathogens were also identified from export quality shrimp samples which may occur due to inadequate processing and transportation. Thus, the presence of pathogens in shrimp samples suggests the fact that proper handling and maintenance is necessary. Another interesting finding of our study reveals that chemical preservatives or antibiotics may be used by the shrimp processing industries to maintain the standard quality. For establishment of the significant validity of this test, further chemical analysis will unveil the accuracy of shrimp processing in future in Bangladesh.

Antimicrobial agents are being used worldwide in aquaculture to present infection. The commonly used antibiotics are sulphonamides, tetracycline, amoxicillin, trimethoprimsulphamethoxine and quinolones ${ }^{11}$. Our results also showed the presence of antimicrobial agents in shrimp samples. However, extensive biological and chemical characterization is required to confirm the presence of a particular agent and its concentration as high concentration of preservative of any type is health hazardous.

\section{Conclusion}

Overall, according to the present study, shrimps of hatcheries and local markets have been found to harbor many pathogens indicating that these are not protected from contamination during subsequent handling, packaging, storage, and transport. Microbiological quality is a very vital aspect of quality control measures; proper handling of fish between capture and delivery to the consumer is a crucial element in assuring quality of the final product. Standard sanitation, handling and the time \& temperature of holding fish are significant factors to ensure quality. Properly controlled monitoring is also required for transportation and storage. If HACCP guidelines are strictly followed during processing and handling, the risk of contamination and outbreak of diseases would be minimized.

\section{References}

1. DoF (Department of Fisheries). 2005. Fish Fortnight Compendium, Department of Fisheries, Ministry of Fisheries and Livestock, Government of the Peoples Republic of Bangladesh.

2. Karunasagar I, Pai R, Malathi GR and Karunasagar I. 1994. Mass mortality of Penaeus monodon larvae due to antibiotic resistant Vibrio harveyi infection. Aquaculture 128: 203-209.

3. Wallace BJ, Guzewich JJ, Cambridge M, Altekruse S and Morse DL. 1999. Seafood-Associated Disease outbreaks in New York, 1980-1994. American J Preventive Med. 17 (1): 48-54.

4. Butt AA, Aldridge KE and Sanders CV. 2004. Infections related to the ingestion of seafood Part I: viral and bacterial infections. The Lancet Infect Dis. 4: 201-212.

5. Huss HH. 1997. Control of indigenous pathogenic bacteria in seafood. Food Control. 8(2): 91-98.

6. Sawhney A. 2005. Quality Measures in Food Trade: The Indian Experience. The World Economy. 28 (3): 329-348.

7. Robinson RK. 1985. In Microbiology of Frozen Food. Elsevier Applied Science Publishers.

8. Antony MM, Jeyasekaran G, Shakila RJ and Shanmugam SA. 2002. Microbiological Quality of Raw Shrimps Processed in Seafood Processing Plants of Tuticorin, Tamil Nadu, India. Asian Fish Sci. 15: 33-41.

9. Rajadurai NP. 1985. Improving the quality of shrimp through proper handling. INFOFISH International. 1: 50-52.

10. CFC/INFOFISH. 1997. CFC/INFOFISH Project on Export Promotion of ValueAdded Fishery Products and their Sustainable Development. Progress Report (1 January - 30 June 1997). Kuala Lumpur, Malaysia: INFOFISH.

11. Angulo F. 1999. Use of antimicrobial agents in aquaculture: potential for public health impact. Division of Bacterial and Mycotic Diseases. Center for Disease Control and Prevention. Accessed 24 August, 2007. 